\title{
Health in the Context of Global Health
}

\author{
Samuel J. Stratton, MD, MPH
}

The term "Global Health" has become popular in the past decade. Schools of tropical medicine have since the 1800 s been engaged in the control of infectious disease around the globe. The original schools of hygiene and tropical medicine have served as a foundation for the development of the broader special area of global health. Global health expands beyond the foundations of infectious disease control and sanitation practice to include the interests of public health, public policy, and the social sciences. While the term "global health" has been in use since the mid-twentieth century, attempts to define the breadth of global health have only recently been made. Some argue that global health is mainstream public health on a global basis, but many understand it to be much broader in scope.

In an editorial published by the Lancet in 2009, Koplan and co-authors convincingly proposed the definition for global health to be:

[G]lobal health is an area for study, research, and practice that places a priority on improving health and achieving equity in health for all people worldwide. Global health emphasizes transnational health issues, determinants, and solutions; involves many disciplines within and beyond the health sciences and promotes interdisciplinary collaboration; and is a synthesis of population based prevention with individual-level clinical care.

In forming this definition, the authors made arguments that global health transcends national boundaries, requires global cooperation for solutions, concerns both prevention and clinical care, and is interdisciplinary and multidisciplinary within and beyond the health sciences. ${ }^{1}$ Koplan and his co-authors emphasized that a primary objective of global health is health equity among nations for all people. ${ }^{1}$

A year following the Koplan paper, a second editorial paper arguing that global health is public health was published in the Lancet. In their 2010 editorial, Fried and co-authors argued that global health is public health. They based their argument on the public health aspects of the assertions made by Koplan and co-authors, as well as the observation that pandemic infectious diseases, such as AIDS and influenza, are not confined to nations; that chronic diseases will grow with an ageing global population; and that evidence suggests that the diet and lifestyle of high-income nations have "communicable" characteristics with examples such as in China, $20 \%$ of men are hypertensive and nearly 80 million people in India will have diabetes by $2030 .^{2}$ Fried and co-authors further argued that global health is public health in that cross-national comparisons of health systems can yield useful insights and that the health workforce is becoming globalized. ${ }^{2}$

An interesting perspective on global health is that developed nations seem to believe that technology, sophisticated delivery of health service, and transference of the health culture of developed nations is the pinnacle of global health. This is most evident in the global response to disaster events that occur in under-developed nations, as was demonstrated in the 2010 Haiti Earthquake.
During this global health crisis, an unorganized international response led to such confusion that the only airport into the country was at times closed because it was over-whelmed with incoming flights of un-invited teams and materials. During the event, medical teams and mobile hospitals competed for patients, delivering temporary sophisticated surgery (frequent amputations) and medical care, only to leave thousands of disaster victims to survive without organized rehabilitation services or medical follow-up following the temporary humanitarian medical care provided immediately following the disaster event. ${ }^{3}$ Opposed to the transference of developed nation technology and systems, the importance of bidirectional sharing of knowledge and global health understanding and the multicultural aspect of health, regardless of wealth and world political balance, is emphasized by Fried and co-authors. ${ }^{2}$

In a 2010 effort to define global health in a concise and operational manner, Beaglehole and Bonita proposed the following: "global health is collaborative trans-national research and action for promoting health for all." ${ }^{4}$ As can be noted from attempts to define global health, there seems to be different interpretations of a term that is now used and referenced in the literature of many disciplines, including health and medicine, political sciences, and social sciences.

Perhaps dividing the term "global health" into its root words will allow for a better understanding of the domain discipline. Most will agree on the meaning of the word "global." Global involves the whole of the world without regard to political or geographic divisions. Beyond "world," global implies not only surface areas, but also the oceans and seas to their depths and the limits of the atmosphere. Global is the earth and all its elements.

Defining health is much more complex and is probably the component of the term "global health" that makes it difficult to define. The official definition of health used by the members of the World Health Organization (WHO; Geneva, Switzerland) is the standard definition generally accepted throughout the world: "Health is a state of complete physical, mental, and social wellbeing and not merely the absence of disease or infirmity." 5 This definition has stood without amendment by the membership of the WHO since $1948 .^{5}$ It is important to recognize that an individual's perception of health likely varies from culture to culture. For example, the understanding of the state of disease and infirmity are as much determined by a particular population's culture as by a world group. In fact, social well-being as used in the WHO definition of health may be defined by one's age and gender by one culture; while in another culture, social well-being may depend less on age and gender and more upon individual wealth or the social hierarchy one is born into. Similarly, mental well-being is based on an understanding provided by culture and may vary from population to population. Health is an individual perception formed by one's culture and overall knowledge base. Considering the factors that determine the perception of health, it can be understood that the term "global health" is a "moving target" that is open to a range of interpretations. 


\begin{tabular}{|c|c|}
\hline Health Indicator & Example \\
\hline 1. Physical Well-Being & $\begin{array}{l}\text { 1. Capable of performing the daily duties of living, including communication with others, obtaining shelter, access to } \\
\text { nutrition, and personal mobility. }\end{array}$ \\
\hline 2. Disease Controlled & $\begin{array}{l}\text { 2. Able to compensate for disease states or challenges, including control of chronic conditions such as diabetes and } \\
\text { prevention of acute disease such as influenza. }\end{array}$ \\
\hline 4. Emotional Well-Being & $\begin{array}{l}\text { 4. The ability to experience satisfaction with one's self with limitation of the experience of depression and anxiety. } \\
\text { Freedom from minimization by others both in employment and daily activities. }\end{array}$ \\
\hline 5. Mental Well-Being & $\begin{array}{l}\text { 5. The ability to perform daily activities as described in \# } 1 \text { above and emotional well-being as described in \# } 4 \text {. } \\
\text { Access to timely mental health care and information. }\end{array}$ \\
\hline 6. Stress-free State & 6. Limited stress in conduct of daily activities. \\
\hline 8. Health Care Access & $\begin{array}{l}\text { 8. Access to preventive health care, timely access to clinical medicine in an affordable manner with safe and best } \\
\text { clinical practices provided. }\end{array}$ \\
\hline $\begin{array}{l}\text { 9. Age Appropriate } \\
\text { Services }\end{array}$ & $\begin{array}{l}\text { 9. Access to the physical and mental health services specific to one's age, such as childhood vaccination, prenatal } \\
\text { care, adolescent access to treatment for potential venereal disease, rehabilitation of middle age injuries, and } \\
\text { palliative care for elderly. }\end{array}$ \\
\hline 10. Health Information & $\begin{array}{l}\text { 10. Ready access to health information and education in a manner that target populations can understand and apply } \\
\text { the information. Including disaster planning and emergency warning systems. }\end{array}$ \\
\hline
\end{tabular}

Table 1. Ten Proposed Primary Indicators of Global Health

In considering the WHO definition of health, it is possible to develop concrete indicators of the overall health of a population. In evaluation of the health of populations, indicators are commonly used by multiple disciplines to compare and discuss general and specific health factors. Epidemiological indicators, such as population fertility, mortality, and morbidity rates, are examples of common indicators that may reflect the health of a population. Table 1 proposes ten indicators of health that possibly extend to all global populations. The ten health indicators are listed to show the magnitude of the concept of global health. As stated in the WHO definition, health is more than a disease-free state without physical or mental disability. Elements of health can be measured and discussed in specific terms. Most importantly, global health indicators allow for study with scientific scrutiny. The indicators in Table 1 can be interpreted either in quantitative or qualitative terms. For example, lack of physical well-being can be measured by those who are reported or known to be unable to maintain employment due to physical infirmity. Disease control is traditionally measured by vaccination rates. Stress or environmental safety can be measured by measures of common elements of

\section{References}

1. Koplan JP, Bond TC, Merson MH, Reddy KS, Rodriguez MH, Sewankambo NK, Wasserheit JN, for the Consortium of Universities for Global Health Executive Board. Towards a common definition of global health. Lancet. 2009;373:1993-1995.

2. Fried LP, Bentley ME, Buekens P, Burke DS, Frenk JJ, Klag MJ, Spencer HC. Global health is public health. Lancet. 2010;375:535-537.

3. Redmond AD, Mardel S, Taithe B, Calvot T, Gosney J, Duttine A, Girois S. A qualitative and quantitative study of the surgical and rehabilitation response to the earthquake in Haiti, January 2010. Prehosp Disaster Med. 2011;26(6):449-456.

4. Beaglehole R, Bonita R. What is global health? Global Health Action. 2010;3:5142 DOI: $10.3402 /$ gha.v3i0.5142. society such as measures of traffic congestion or water purity. Other health indicators, such as social support, emotional well-being, and mental health, are appropriate for qualitative analysis.

In the field of global health, there is a robust literature that is focused on health emergencies and disasters. This issue of Prehospital and Disaster Medicine is dedicated to that literature. In this issue, research focused on developing areas of the world is presented. Readers should not only read the papers for their specific scientific objectives, but also notice descriptions of emergency and disaster response systems in areas of the world for which there is scant health and medical literature. The emergency health issues described by authors in this issue are extraordinary and illustrate the breadth and scope of true challenges in global health. Prehospital and Disaster Medicine has published international and global health papers for the past thirty years. The literature in this issue is not a new genre for the journal; rather, it has been complied to provide a concentrated focus on global health and recognition of the work and research conducted by colleagues in demanding locations of the globe.

5. World Health Organization. Preamble to the Constitution of the World Health Organization as adopted by the International Health Conference; New York USA: June 19-22, 1946; signed on July 22, 1946 by the representatives of 61 States (Official Records of the World Health Organization, no. 2, p. 100) and entered into force on April 7, 1948. WHO Web site. www.who.int/about/definition/en/print.html. Accessed October 24, 2015.

Online publication: November 11, 2015 doi:10.1017/S1049023X15005373 